\title{
Editorial
}

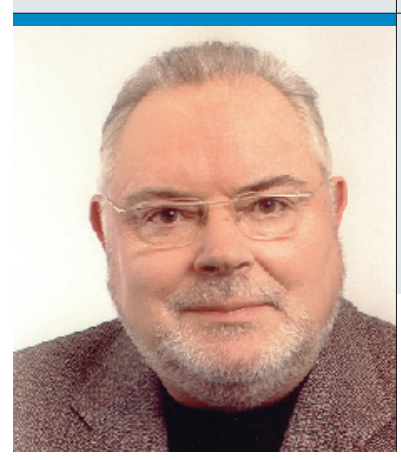

"Nichts ist so gut, dass man es nicht noch besser machen könnte. Deshalb haben wir versucht, die HNO-Nachrichten noch interessanter und lesenswerter zu gestalten."

Dr. med. Dieter Leithäuser,

Chefredakteur und HNO-Arzt, Warburg

\section{Dezente Verjüngungskur}

W er rastet, der rostet, und eine Zeitschrift, die sich nicht weiterentwickelt, ist schnell veraltet. Dieses Schicksal wollten wir den HNONachrichten ersparen und haben sie deshalb einer kleinen Auffrischungskur unterzogen. Im Großen und Ganzen sind es nur kleine, aber - wie wir finden - feine Änderungen:

_-Am Anfang des Heftes lesen Sie auch weiterhin die bunten Meldungen aus Medizin und Gesundheitspolitik. Sie laufen nun aber unter der Bezeichnung „Panorama“.

_ Daran anschließend findet sich eine Neuerung, die Ihnen vielleicht etwas mehr auffällt: die neue Rubrik „Im Blickpunkt“. Hier werden unter anderem Beiträge aus Springer-Fachzeitschriften mit eher klinischem Fokus wie der Zeitschrift HNO oder auch aus Titeln verwandter Fachgebiete von unseren Medizin-Journalisten für Sie zusammengefasst und auf den Punkt gebracht. Wir starten in diesem Heft mit einem Beitrag zum Akustikusneurinom. _ Der Fortbildungsteil ist künftig in der ersten Hefthälfte platziert und beginnt mit der Rubrik Literatur kompakt. Danach folgen die Blickdiagnose und die Fortbildungsbeiträge, so wie Sie es auch bisher gewohnt waren, in diesem Heft mit dem Schwerpunkt „Kinder“.
_ Im Anschluss an den Fortbildungsteil finden Sie künftig in der einen oder anderen Ausgabe dann wieder eine neue Rubrik: Unter „Medizin aktuell“ bieten wir Ihnen zum Beispiel Kongressberichte oder Interviews zu aktuellen Themen.

—Danach finden Sie in der Rubrik „Praxis konkret“ die Themen zum Praxismanagement, die bisher im ersten Teil des Heftes platziert waren, und in der Rubrik „Pharmaforum“ die Berichte und Meldungen, die Sie bisher unter der Rubrik „Medizin und Markt" lesen konnten.

_Zum Abschluss und Ausklang bieten wir Ihnen auch weiterhin die feuilletonistischen Beiträge, wie Sie sie aus der bisherigen Rubrik „Magazin“ kennen, die nun aber Prisma heißt.

Wir hoffen, dass diese Frischzellenkur Ihre Zustimmung findet und wünschen Ihnen viel Freude beim Lesen.

Ihr

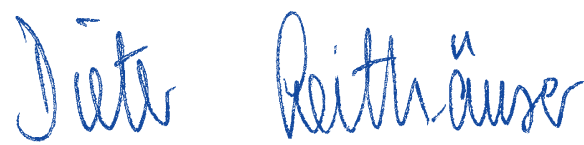

